\title{
Visual search, complex backgrounds, mental counters, and eye movements*
}

\author{
JOHN D. GOULD $\dagger$ and ROLAND CARN \\ Carnegie-Mellon University, Pittsburgh, Pennsylvania 15213
}

\begin{abstract}
For 30 days, three $S s$ searched for 1, 5, or 10 targets $(\mathrm{N})$, any one of which had to occur once (as in past research), twice, or four times (FREQ). The $N=1$ and $N=5$ items were subsets of $N=10$ items. When $F R E Q=1, S s$ searched longer for 5 targets than for 1 or 10 targets. This nonintuitive result was due to (a) Ss searching for all 10 targets even at $N=5$, and (b) the reported "pop-out effect" of the 5 target items as well as the other 5 items in the $N=10$ set. When FREQ $>1$, Ss could search for only 2-3 targets at once, because they could not keep mental counters on more items. The presence of a complex background merely added a constant to search time. The main change in eye movements, with 30 days' practice, was to reduce greatly the number of eye fixations, thus suggesting an increase in the useful field of view and/or a change in search strategy. A speculative model, based upon two comparison processes, was suggested to explain the results.
\end{abstract}

Several recent experiments have studied the effects of requiring $S$ s to search simultaneously for different numbers $(\mathbf{N})$ of targets. The usual finding is that search time is proportional to the number of different targets searched for (Graboi. 1971: Wattenbarger, 1968; Yonas \& Pittinger, 1970). although in some circumstances search time is independent of $\mathrm{N}$ (Neisser, Novick, \& Lazar, 1963). In these studies, smaller target sets, e.g., $\mathrm{N}=1$ or $\mathrm{N}=5$, were always subsets of each S's maximum target set. e.g. $\mathrm{N}=10$. In conditions in which $\mathrm{S}$ was searching for a subset of targets (e.g., $\mathrm{N}=5$ ), items that were in his maximum target set, but not in this subset, were never displayed. For lack of a better name, these items will be called "nontarget targets." By displaying these nontarget targets, an interesting theoretical question can be addressed. When $\mathrm{N}=5$, for example, and $S$ fixates a nontarget target, will he (a) immediately reject it ["preattentively," as Neisser (1967. p. 100) suggests] or (b) initially process it as a target set item and then reject it at a later stage of processing? Loosely speaking, do practiced Ss always look for their maximum target set even when they are required to look only for a subset?

Previous studies of visual search required Ss to detect only a single occurrence of a target before classifying the stimulus as positive. The present experiment investigates this case (i.e., FREQ = 1), as well as two cases (FREQ = 2 or 4 ) in which Ss must detect more than one occurrence of a particular target before they classify the stimulus as positive. The prediction was that this would change the task dramatically. No longer would the task

*This research was conducted while the first author was Visiting Associate Professor of Psychology at Carnegie-Mellon University. It was partially supported by the National Institute of Mental Health. Grant MH-07722. We thank Stephen Ellis, Lee W. Gregg, Stephen J. Bojes, and especially J. Patrick Cavanaugh, for their useful comments on the first version of this paper.

+ Present address, from which reprints may be obtained: IBM Corporation, T. J. Watson Research Center, P.O. Box 218, Yorktown Heights. New York 10598. involve just visual search (i.e., moving the eyes from place to place on the display and encoding the fixated items) and memory search (i.e., comparing each fixated item with each of the target set items; cf. Sternberg. 1971). Now Ss must count or keep track of the frequency of occurrence of each different target as they search the display. Previous experiments (Monty, Taub, \& Laughery, 1965; Yntema, 1963; Yntema \& Schulman, 1967), not done in a visual search context and not using practiced Ss, have shown that keeping track of the state of as many as three or four different variables overloads short-term memory and leads to many errors.

A third question studied was the changes that S's eye movements undergo after many "days" of visual search practice. Visual search times get two to five times faster after several sessions of practice (Neisser et al, 1963: Wattenbarger, 1968). Is this correlated with a change in the spatial pattern of eye movements with practice and/or with a change in fixation durations?

A fourth question sutied was how Ss' performance when searching stimuli having plain backgrounds (the usual laboratory case) compares with Ss' performance when searching stimuli having a complex background (the usual case in visual inspection applications, e.g., Erickson. 1964, 1965; Schoonard \& Gould, 1973: Smith et al, 1962).

\section{METHOD}

The two Es and one female undergraduate served as Ss. On each of 30 days, each $S$ searched 14 stimuli at each of nine experimental conditions ( $N=1,5$, or 10 , and $F R E Q=1,2$, or 4). The days were usually consecutive calendar days, but some exceptions occurred, including a break of 1 and 3 weeks, respectively. for two of the $S s$. The $S$ s were instructed to search as fast as they could but to try to make no more than one error on a series of 14 stimuli. The nine conditions of $N$ and FREQ were presented in an order such that $S$ s were given the same value of $\mathrm{N}$ for three consecutive conditions of FREQ (42 stimuli). The order of $N$ and the order of FREQ within $N$ were balanced across $S s$ and across days. 


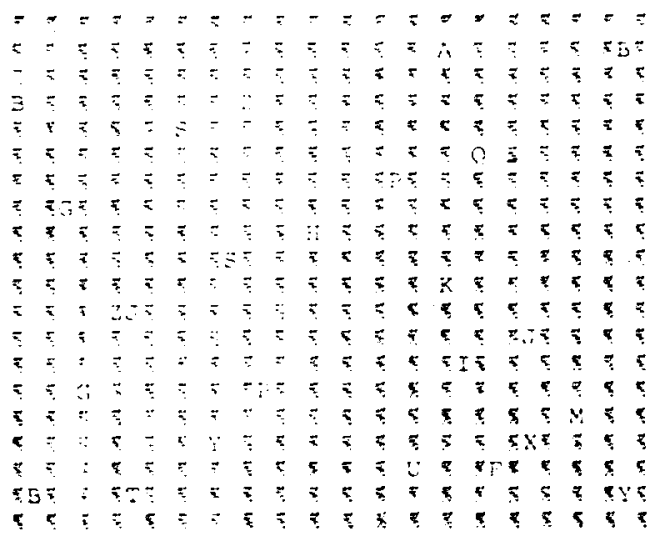

Fig. 1. Schematic representation of a complex background display. A plain background display did not contain $\%$ signs.
A stimulus always contained 25 uppercase alphabetic characters displayed randomly in any of 800 character positions on a square 16.5 -deg computer-controlled raster-type cathode ray display located just above eye level. The "high-contrast" characters appeared bluish-white on a dark background and subtended about 33 min vertically at S's eye.

Half the stimuli in a series of 14 were positive and half were negative. The $S$ s pushed one button if the stimulus was positive (i.e.. one target appeared FREQ times) and pushed a different button if it was negative (i.e.. no target appeared FREQ times).

On "odd" days. a stimulus contained the 25 characters. whereas on "even" days, the stimulus contained, in addition, a "complex" background. The latter, shown schematically in Fig. 1, was a vertical grating in which the odd columns were blank and the even columns contained \% signs. The 25 characters could appear in either type of column.

Thus, the factorial desion contained seven variables: Ss (3). N $(1,5,10)$. FREQ (1, 2, 4), trials (1 to 7 ), stimuli (positive or negative). background ( 2 kinds), and days ( 1 to 15 ). A glance at Fig. 2 shows the obtained data, summed over $\mathrm{S} s$ and trials. for five of these variables.

Eighteen different uppercase alphabetic characters were used (A B F G H I J K L II P Q S T U XY Z). These remained after informal evaluation had eliminated the other eight due to potential visual confusions. Each S's memory set of 10 characters was different from the other two Ss', and it remained

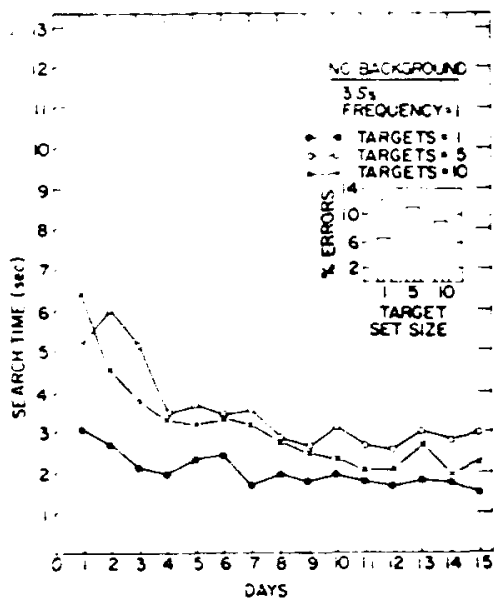

(a)

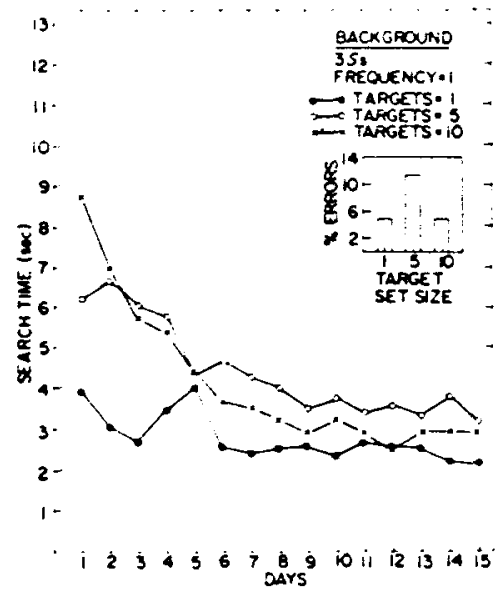

(d)

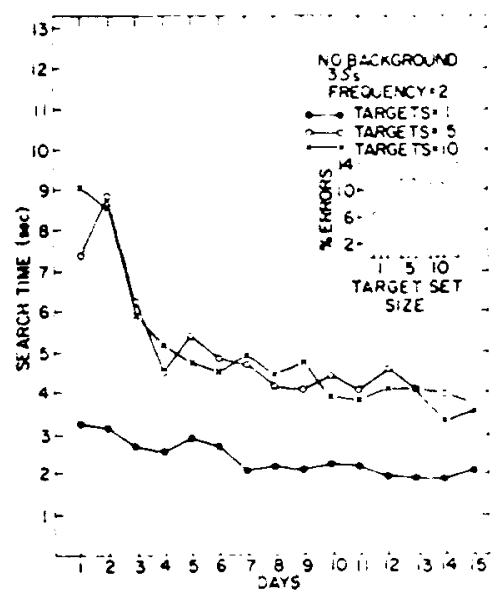

(b)

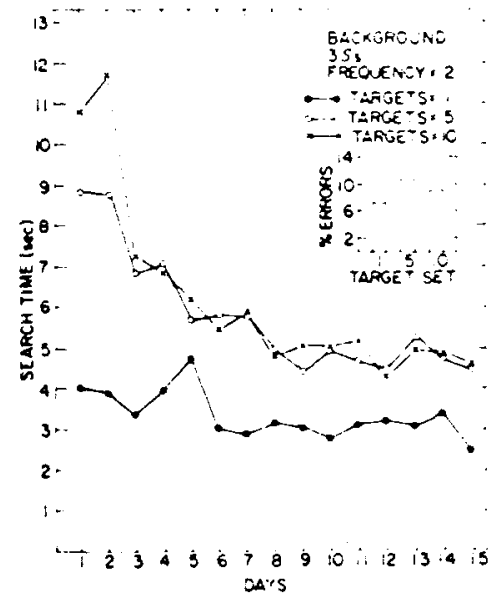

(e)

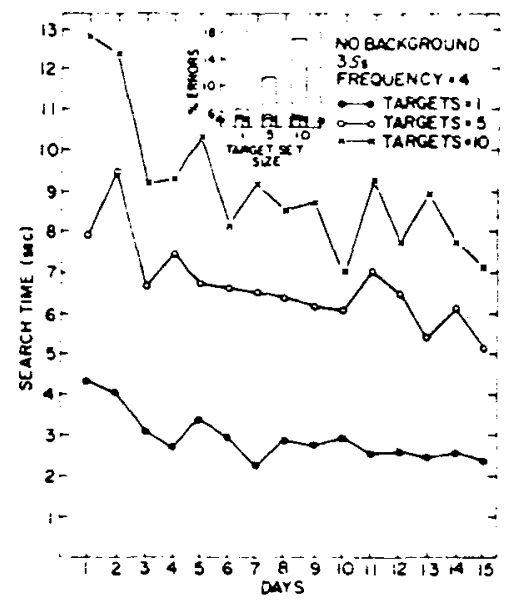

(c)

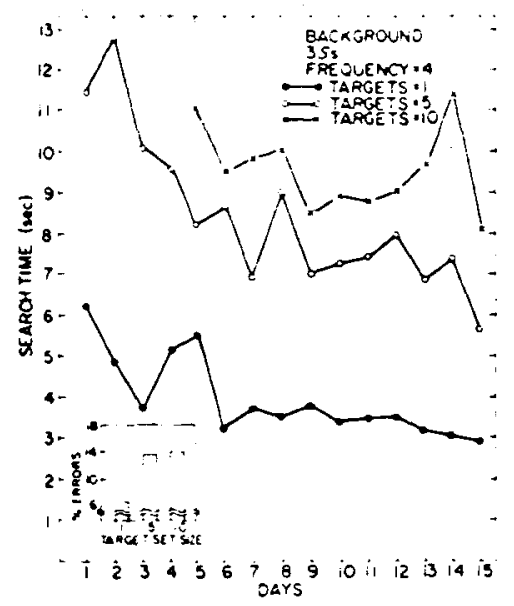

(f)

Fig. 2. Search times and errors as a function of practice. The upper three panels show results obtained with plain background and the lower three panels show results obtained with the complex background. 
unchanged throughout the experiment. These were A GH N P $T$ L I Z : I B I ; 11 \QS T L : and B F I J K L P Q X Z). The usc of a convtant target ict leads to faster scanning than does the use of different turget ets (Metlay. Sokoloff, \& Kaplan, 1970). It is also comistent with visual inspection applications.

A different ubset of $N=1$ and $N=5$ was selected from each S's 10-item turget ict ach day. The $N=1$ subset was never contained in the day,$x=5$ subset. Selecting these subsets from the maximum-size memory set. rather than from other characters, may provide a bias in the direction of simultaneous or parallel warch for multiple targets. since this was the procedure of Xejsser, Novik, and Lazar (1963). Unlike their study. however. different subsets were used each day to prevent additional ipecific practice on certain targets and to avoid the possibility of selecting atypical targets. This introduces at least a twofold bias. The Si did not gain as much specific practice at $N=1$ and $X=5$ as at $N=10$. and specific practice leads to faster scanning. Second. Ss' memory and search processes for $\mathrm{N}=10$ were probably aided by searching for subsets of it compared to what they would otherwise be if $\mathrm{S}$ did not have this additional practice.

The experiment was controlled by the Carnegie-Mellon University Psychology Department computer system, which is under the direction of Professor Lee Gregg, and was programmed with Allen Pinkus' APCOL on-line programming language.

A stimulus was generated by (a) deleting the $\mathrm{N}$ target characters in the condition from the set of 18 characters; (b) creating a list. called the "display list," of 25 characters selected randomly with replacement from these $(18-\mathrm{N})$ characters: (c) selecting randomly a target item from the $\mathrm{N}$ target set items: (d) replacing. on positive stimuli, FREQ items on the display list with the target character or replacing, on negative stimuli, a random number of items, between 0 and (FREQ - 1). with the target character.

At this point, the display list contained FREQ or fewer occurrences of the target and 21-25 occurrences of the (18-N) characters not in the set of $\mathrm{N}$ items $\mathrm{S}$ was searching for. These $(18-N)$ items consisted of nontargets (the 8 items not in S's 10 -item target set) and, in the six conditions in which $\mathrm{N}=1$ or $\mathrm{N}=5$, "nontarget targets."

A fifth step in stimulus generation occurred in four conditions $(\mathrm{N}=5 . \mathrm{FREQ}=2 ; \mathrm{N}=5 . \mathrm{FREQ}=4 ; \mathrm{N}=10, \mathrm{FREQ}=2 ; \mathrm{N}=10$, $\mathrm{FREQ}=4$ ). A random number of occurrences of other items from the $\mathrm{N}$-item target set were selected to replace some of the original nontarget items in the display list. A random number between 0 and (FREQ - 1) of each of these items was selected. These were essentially a fourth class of displayed items, namely target set items that did not occur the critical number of times.

Random X-Y locations for each of these 25 display list items were selected and, on "even" days, merged inside the computer with the complex background described above.

At the beginning of a condition. the target set was displayed, and $S$ had as much time as he wanted to memorize it (he could also write it down). He then pressed a button which caused the first stimulus to be displayed 4-5 sec later. The stimulus was terminated when $\mathrm{S}$ responded. He was then given feedback on his search time and correctness. Another stimulus was automatically displayed $4-5 \mathrm{sec}$ later. This continued for the entire condition of 14 stimuli. Following completion of a condition, S started the next condition when he was ready.

The Ss wrote notes on their introspections between conditions. Each $S$ also kept a daily log of his search time and errors, as printed out by the computer. The motivation was to reduce search time and to monitor error levels.

To assess changes in visual search with practice, eye movements were recorded on two to four stimuli at each value of FREQ, N, and background after each $S$ had been in the experiment for about 2 days and again after the completion of the experiment. The closed-circuit television corneal-reflectance eye-marker system described earlier (Gould \& Peeples. 1970) was used. This recorded fixation durations in $16-\mathrm{msec}$ intervals.
Table 1

Mean Number of Eye Fixations Before and After 30 Days Practice

\begin{tabular}{|c|c|c|c|c|c|}
\hline & & \multicolumn{2}{|c|}{ No Background } & \multicolumn{2}{|c|}{ Background } \\
\hline & & Before & After & Before & After \\
\hline $\mathbf{N}$ & $\begin{array}{r}1 \\
5 \\
10\end{array}$ & $\begin{array}{l}10.4 \\
22.0 \\
24.3\end{array}$ & $\begin{array}{r}7.5 \\
11.4 \\
14.5\end{array}$ & $\begin{array}{l}10.6 \\
21.6 \\
34.0\end{array}$ & $\begin{array}{l}10.0 \\
15.9 \\
18.7\end{array}$ \\
\hline$F$ & $\begin{array}{l}1 \\
2 \\
4\end{array}$ & $\begin{array}{l}11.5 \\
18.8 \\
26.2\end{array}$ & $\begin{array}{r}6.6 \\
11.7 \\
15.1\end{array}$ & $\begin{array}{l}15.6 \\
20.5 \\
30.2\end{array}$ & $\begin{array}{l}10.4 \\
13.8 \\
20.3\end{array}$ \\
\hline
\end{tabular}

\section{RESULTS}

Averaged over all conditions, Ss required $4.99 \mathrm{sec}$ to search, and they misclassified $9.6 \%$ of the stimuli. Ss reported that their errors fell into two main subjective categories: (a) when FREQ $>1, N>1$, and $S$ had low confidence in his decision; (b) when $S$ was in the process of pressing the negative button and he detected the target, but could not stop his movement. The Ss were rarely surprised when they were informed of an error. ${ }^{1}$

\section{Practice}

As is always found (Neisser, 1963; Neisser, Novick, \& Lazar, 1963; Wattenbarger, 1968; Yonas \& Pittinger. 1970), search times became much faster with many days' practice [cf. Figs. 2a-2f; $F(14,28)=14.75$, $p<.001]$. Errors remained constant, however. Search times were nearly constant within a condition of 14 trials.

At the level of eye movements, this reduced search time was due primarily to a reduction in the number rather than the duration of eye fixations. Table 1 shows that at the beginning Ss made between 10 and 34 eye fixations on the 25 -item stimuli. With practice, Ss almost halved this number, which suggests that their useful field of view increased in size and/or their search sirategy improved. The general sequence of each S's eye fixations was influenced both by where the characters were displayed and by a gross scanning stretegy (e.g., top to bottom). At the end of the experiment, Ss were still making more fixations on stimuli with the complex background than on stimuli with the plain background, probably because the complex background reduced their useful field of view.

Table 2 shows that fixation durations decreased only slightly $(35 \mathrm{msec})$ with practice. Of more significance, however, is that these fixation durations were $100-200 \mathrm{msec}$ shorter than (a) those found in an experiment in which Ss were required to fixate, in a prescribed order, a display of 12 alphabetic characters while searching for target characters (Gould, 1973): or (b) finger reaction times typically found in item-recognition tasks (cf. Sternberg, 1971). This faster processing may be due to Ss' selectively fixating items in 
Table 2

Mean Duration (Milliseconds) of Eye Fixations Before and After 30 Days Practice

\begin{tabular}{|c|c|c|c|c|c|}
\hline & & \multicolumn{2}{|c|}{ No Background } & \multicolumn{2}{|c|}{ Background } \\
\hline & & Before & After & Before & After \\
\hline$N$ & $\begin{array}{r}1 \\
5 \\
10\end{array}$ & $\begin{array}{l}316 \\
320 \\
329\end{array}$ & $\begin{array}{l}271 \\
283 \\
293\end{array}$ & $\begin{array}{l}325 \\
333 \\
322\end{array}$ & $\begin{array}{l}294 \\
296 \\
292\end{array}$ \\
\hline $\mathbf{F}$ & $\begin{array}{l}1 \\
2 \\
4\end{array}$ & $\begin{array}{l}336 \\
308 \\
322\end{array}$ & $\begin{array}{l}280 \\
280 \\
286\end{array}$ & $\begin{array}{l}327 \\
333 \\
319\end{array}$ & $\begin{array}{l}282 \\
295 \\
305\end{array}$ \\
\hline
\end{tabular}

this free search situation to take better advantage of the (not-yet-understood) relationships among the sensory factors in foveal vision and peripheral vision and the cognitive factors in focal attention. Alternatively, it may simply be due to a speed accuracy tradeoff.

The Ss reported that for the first 6-10 days (half in each background condition), they silently and continually said each letter of the 10-target set to themselves. During the remaining 20 days or so, they no langer rehearsed the 10-target set. Graboi (1971) also noted this change. These characters were reported to "pop out" from the stimulus, just as Neisser (1963) as well as others (Briggs \& Blaha, 1969; Cavanaugh \& Chase, 1971: Graboi. 1971) have reported. The improvement in search times with practice cannot be entirely attributed to lack of rehearsal, however (Graboi, 1971).

Unlike the 10-item target set. Ss reported that they rehearsed the 5-item target sets continually. The 5 target characters were reported to pop out from the screen. Of more significance, however, was the report that the 5 nontarget targets also popped out. This introspective result was compelling.

When $N=1$. Ss were not sure how much, if any, they rehearsed the target item on the last 20 days. Graboi (1971) also found different subjective reports for $\mathrm{N}=1$ than for larger target sets.

\section{Background}

As shown in Figs. 2a-f and $3 b$, the complex background added a constant of about $1 \mathrm{sec}$ to search times [means $=5.56$ vs $4.42 \mathrm{sec}: F(1.2)=18.02$. $p<.06]$. In line with the instructions, errors were about the same (cf. Fig. 2 inserts). The number of eye fixations was greater on the complex background (Table 1), but the durations of eye fixations were about the same on the plain and complex backgrounds (Table 2). Background had no interactive effect on any variable in this experiment. ${ }^{2}$ The significance of this is that conclusions to be drawn about the effects of $\mathrm{N}$ and FREQ are independent of the background variable.

\section{Frequency $=1$}

When FREQ $=1$ (Figs. 2a, 2d, 3a), search for 5 targets was slower than search for either 1 target or 10 targets! Errors followed the same trend. Search times for $\mathrm{N}=1$ were faster than search times for $\mathrm{N}=10$ on each day $\left(\mathrm{p}=2^{-15}\right){ }^{3}$

The finding that Ss required more time and made more errors when searching for 5 targets than when searching for 10 targets is new and nonintuitive. There are two explanations of this result. First, Ss' verbal reports indicated that this result was due to the interference effect caused by the presence of nontarget targets when $N=5$. It was frequently reported that when one of these nontarget targets was fixated, $\mathrm{S}$ had "to stop and think whether it was really a target or not." "I had to compare the result in my visual memory with the items I was rehearsing in my acoustic memory."

The other explanation involves differential amounts of specific practice (Metlay, Sokoloff, \& Kaplan, 1970). Although the items in each target set size remained the same for 42 consecutive trials each day, the items in the 1. and 5 -item sets changed from day to day, whereas the items in the 10 -item set remained the same every day. This explanation is weakened by Graboi's (1971) finding
Fig. 3. Search times and errors on the last 5 days with the complex background (B) and with the plain background $(\bar{B})$. Figure 3a is summed over backgrounds and Fig. 3b shows performance at each background separately. The parameter is the frequency with which any target must be detected.
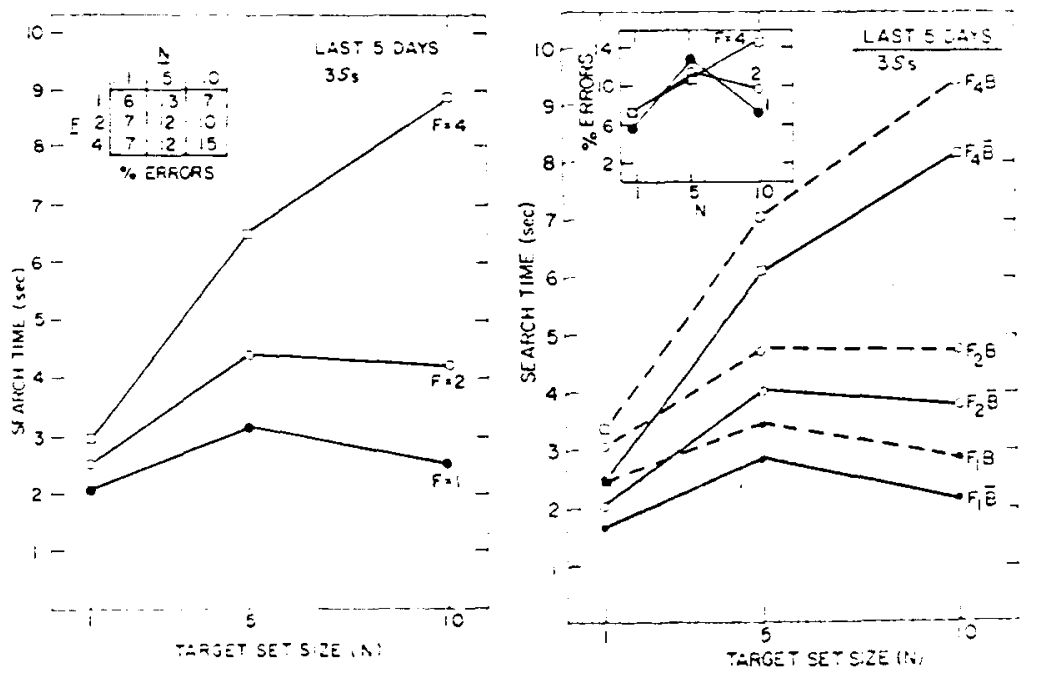
that when the amount of practice in searching for specific items in a set is varied, the search rate for each itcm in that set is still about the same for practiced Ss.

These results provide some additional evidence that Neisser's results, which suggest parallel scanning for multiple targets, probably occur only in limited circumstances. Wattenbarger (1968) found scan time to be proportional to $\mathrm{N}$ when Ss were given an "accuracy" set, but not when Ss were given a "speed" set. The former group made $7 \%$ errors; the latter group made $15 \%$ errors; our Ss made $9.6 \%$ errors; Neisser's Ss, who were given a "speed" set, made in excess of $20 \%$ errors.

\section{Frequency $>1$}

As shown in Figs. 2 and 3, the important effect of requiring Ss to find more than one occurrence of an individual target was to increase search times greatly [for all 15 days, $F(2,6)=114.66 ; p<.001]$. Error rates increased only modestly [for all 15 days, $F(2,6)=8.80$; $p<.05$ ], consistent with the instructions to keep them constant in all conditions. When FREQ $=2$ (Figs. $2 b$ and 2e), search for a single target was much faster than search for 5 or 10 targets, which times were the same (Duncan range tests). When FREQ $=4$ (Figs. 2c and 2f), search for 1 target was faster than search for 5 different targets, which in turn was faster than search for 10 different targets (Duncan range tests).

\section{$\mathrm{N}$ by FREQ Interaction}

Figure 3 shows that search times on the last 5 days depended upon the combined effect of $\mathrm{N}$ and FREQ $[F(4,8)=73.37: p<.001]$. This interaction, together with that shown in Fig. 4 [N by FREQ by Pos-Neg Stimuli, $F(4,8)=5.98 ; p<.05]$, is key to understanding Ss' behavior.

At $\mathrm{N}=1$ (Fig. 3a), with each increment in FREQ, there is a relatively small increase in search time (about $.3 \mathrm{sec}$ ) and no increase in errors. This increase in search time was probably influenced by four factors:

\section{(1) Counting}

When FREQ $>1$, Ss must count the occurrences of the target.

\section{(2) Identification}

When FREQ $=1$, Ss sometimes signal the occurrence of a target before they can identify it (Neisser, 1963). whereas when FREQ $>1$, Ss must identify the target before counting it. ${ }^{4}$

\section{(3) Memory' of Search Sequence}

When FREQ $>1$, Ss must remember where on the stimulus they have already found a target. so as not to recount the same item.

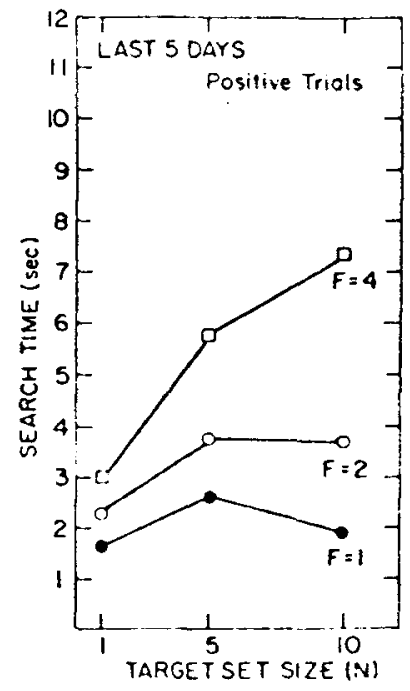

(a)

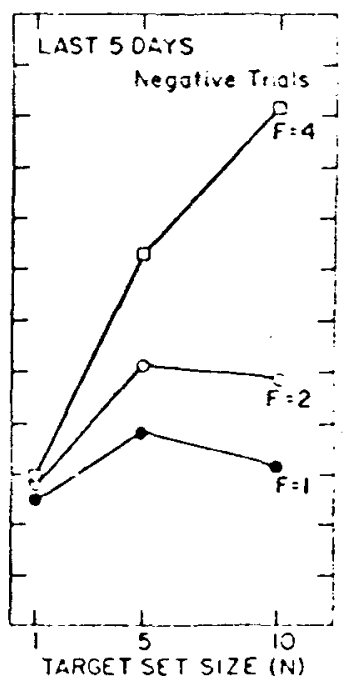

(b)
Fig. 4. Search times on the last 5 days on positive trials (a) and negative trials (b) as a function of target set size. The parameter is frequency with which any target must be detected.

\section{(4) Longer Positive Trials}

Each increase in FREQ requires $S$ to search for a greater average number of stimulus items on positive trials, and search times in Fig. 4 indicate this.

At $\mathrm{N}=5$ (Fig. 3a), there is about a $1.1-\mathrm{sec}$ increase in search time with each increment in FREQ. This increase in search time was probably due to the above four factors and to a fifth factor.

\section{(5) Limited Number of Mental Counters}

Ss must now keep mental counters on up to 5 different targets. They reported, however, that they could keep track of only 2 , sometimes 3 , different targets at once. Monty, Taub, and Laughery (1965), Yntema (1963), and Yntema and Schulman (1967) showed that keeping track of more than two to three variables leads to errors, and the present results show that this limitation exists even after 30 days of practice. As Tables 1 and 2 show, Ss make additional eye fixations of the same duration as FREQ increases, which reflect additional search of the stimulus.

Finally, consider $\mathrm{N}=10$ (Fig. 3a). ${ }^{5}$ When $\mathrm{N}=10$. the increase in search time per increment in FREQ was $2.1 \mathrm{sec}$, or about twice as great as when $N=5$. Since $S$ s could keep track of only two to three targets at once (when FREQ $>1$ ), they had to make more searches through the stimulus at $\mathrm{N}=5$.

The combined effect of $N=10$ and $F R E Q=4$ led to a serious decrease in performance. The search time data points in Figs. 3a, 3b, 4a, and $4 b$ that represent this condition are significantly different from all others (Duncan range tests). Fifty percent more eye fixations 
occurred than were found in any other condition. The error rates jumped to $25 \%$ on positive trials and $5 \%$ on nsegative trials [ $\mathrm{N}$ by FREQ interaction, $\mathrm{F}(4,8)=4.67$ : $p<.05]$. Ss reported that occasionally when they fixated a target in this condition they could not remember whether they had counted it before or not.

\section{Positive vs Negative Trials}

As expected. scanning was faster on positive trials (Fig. 4a, mean $=3.55 \mathrm{sec}$ ) than on negative trials (Fig. $4 b$, mean $=4.73 \mathrm{sec}$ ) $[F(1,2)=20.22: p<.05]$. Most errors occurred on positive trials, just as Neisser (1963) found. On the last 5 days there were $16.2 \%$ errors on positive trials and $3.5 \%$ errors on negative trials.

\section{SUMMARY AND DISCUSSION}

Perhaps the most interesting results are: (a) When FREQ $=1$ (the usual visual search case), search times were longer at $N=5$ than at $N=1$ or $N=10$. (b) Ss reported that nontarget targets, as well as targets. popped out from the stimulus. (c) When FREQ $>1$, Ss could keep track of only 2.3 targets even after 30 days of practice. And (d) the presence of a complex background merely added a constant to search times.

The last finding is more easily explained than the others. During an eye fixation, $\mathrm{S}$ encodes $\mathrm{C}$ characters (where $\mathrm{C}=1.3$ based upon eye-movement data). Noisy. features in or around fixated characters are stripped away during this encoding stage, which now takes longer, and they have no effect on the subsequent memory comparison stage (Chase, 1969: Sternberg. 1967; Gould, 1973). In this free search study, the complex background, rather than causing Ss to fixate each item longer, as would be expected on the basis of the above results on visual noise, caused $S s$ to make more eye fixations. Presumably, this reflects a reduction in the size of the useful field of view.

One explanation of the first three results depends upon the speculative suggestion that the C-encoded "pure" forms or feature lists undergo two parallel memory comparison processes, as indicated in Fig. 5.6

In one comparison process (called visual comparison); the $C$-encoded characters are assumed to be compared with each item in the maximum (10-item) target set. This may seem nonparsimonious or even silly when, for example, $\mathrm{S}$ is looking for only 5 targets. But, in previous studies of well-practiced Ss, nontarget targets were never displayed, and it is the presence of these that provides search-time data and strong introspective reports that lead to this conclusion. Previously reported anecdotal evidence supports this conclusion also. Graboi (1971) reported that Ss have a hard time remembering target items when they are a subset of the maximum target set. Neisser et al (1963) noted that when $S$ was given a stimulus that contained a target other than the one he expected, he usually detected it anyway. This comparison process is called visual, because it is assumed that it is responsible for the phenomenal pop-out effect. ${ }^{7,8}$ In addition. Ss do not rehearse the maximum target set after several days of practice: lack of rehearsal is characteristic of memory for pictures or forms but not for verbal materials (Shaffer \& Shiffren, 1972). Visual comparison can be thought of as the lower levels of Neisser's (1967) extension to visual search of Selfridge's pandemonium model.

The other comparison process (called auditory comparison) involves the comparison of the $C$ pure forms with each item that is being actively rehearsed in an auditory short-term memory. In the case of FREQ = 1 and $N=5$. for example, the comparison is with each of the 5 target set items. On the other hand, when both FREQ $>1$ and $N>1$, then $S$ can keep count or track of only 2-3 different targets at once. The list of these items is called the "current list," and the auditory comparison is assumed to be with each item on this list. Unlike in the visual comparison process, it is assumed that identification of the target's name occurs in this auditory comparison process. Posner and Mitchell's (1967) distinction between form comparison and name comparison is an appropriate analogy.

How do Ss detect a target? In the single case of FREQ $=1, N=10$, a visual comparison is sufficient, since there is no logical requirement for identification here. Also, an auditory match would require that Ss rehearse all 10 items. In all other cases, the outcome of the auditory comparison checks the results of the visual comparison process, as suggested by the first diamond in the "decision box" of Fig. 5. Visual comparison is assumed to be faster than auditory comparison, since Ss can compare characters faster on the basis of their forms than on the basis of their names (Posner \& Mitchell, 1967).

When $\mathbf{N}$ is small, it assumed that the few-item (i.e.. one in this experiment) auditory short-term memory comparison process is completed before the 10 -item visual long-term memory comparison process. Hence, search times are faster when $\mathrm{N}$ is small than when $\mathrm{N}=$ 10. This also explains the relative lack of a reported pop-out effect for other members of the maximum target set when $N=1$. When $N$ is larger, however, the visual comparison process is completed more quickly than the auditory one. Hence, any of the 10 target items can pop out. But, as in the case of $\mathrm{N}=5$ in this experiment. $\mathrm{S}$ must wait until the auditory comparison process is completed before determining whether the popped-out item is a target or a nontarget target. Without this check, $\mathrm{S}$ would signal too many false positives.

When FREQ $>1$, an auditory comparison is required even when $N=$ maximum, because $S$ must identify the target item and then place it in the appropriate mental counter. The mental count of that matched target is then incremented by one. Unless FREQ occurrenes of 
this target have been detected, $\mathrm{S}$ prepares to refixate, and this process is influenced by peripheral vision (cf. Gould, 1969, 1973: Williams, 1967). Prior to refixation, the contents of the current list may have to be modified, as indicated by the lowest main box in Fig. 5, if FREQ occurrences of a target have not been found and all $\mathrm{N}$ items have not been searched for.

Why two comparison processes rather than just one? Although there is no direct evidence in this study for two processes (or for one), the assumption of two processes explains simply the many otherwise less easily reconciled results. A visual comparison process is consistent with the evidence on (a) searching for the maximum set of targets, even when $\mathrm{N}<10$; (b) the pop-out effect of nontarget targets; and (c) no rehearsal of the maximum set size. An auditory comparison process is consistent with the evidence on (a) target identification requirements, and (b) rehearsal requirements for $\mathrm{N}=5$ and for the current list. Together, they can explain, for example, the longer search times (when FREQ $=1$ ) for $\mathrm{N}=5$ than for

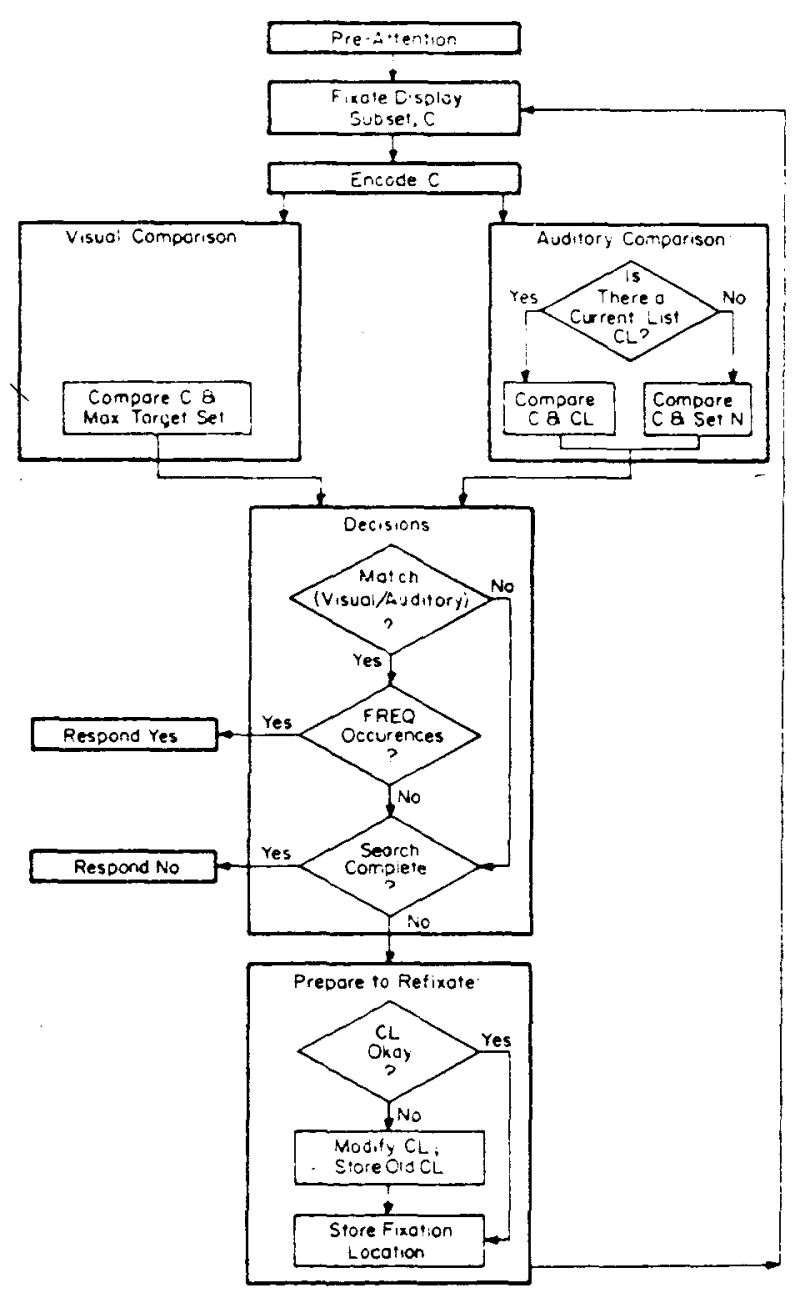

Fig. 5. Flow diagrams possibly describing information processing in this experiment.
$\mathrm{N}=10$. Evidence is accumulating for different memory mechanisms for aural or verbal material and for visual or pictorial material, even though in some "deep structure" sense they may be represented the same way (cf. Boies, 1969; Brooks, 1968; Segal \& Fusella, 1970; Shaffer \& Shiffren, 1972).

\section{REFERENCES}

Boies, S. J. Retention of visual information from a single letter. Unpublished master's thesis, University of Oregon, 1969.

Briggs, C. A., \& Blaha, J. Memory retrieval and central comparison times in information processing. Journal of Experimental Psychology, 1969, 79, 395-402.

Brooks. L. R. Spatial and verbal components of the act of recall. Canadian Journal of Psychology, 1968, 22, 349-368.

Cavanaugh, J. P., \& Chase, W. G. The equivalence of target and nontarget processing in visual search. Perception \& Psychophysics, 1971, 9, 493-495.

Chase, W. G. Parameters of visual and memory search. Unpublished PhD dissertation, University of Wisconsin. 1969.

Erickson, R. A. Visual search for targets: Laboratory experiments. NAVWEPS Report 8406, China Lake, California, 1964.

Erickson, R. A. Visual detection of targets: Analysis and review. NA VWEPS Report 8617, China Lake, California, 1965.

Gould, J. D. Eye movements during visual search. In H. W. Leibowitz (Ed.). Proceedings of 1969 NATO symposium on image evaluation. Munich. Germany, 1969.

Gould. J. D. Eye movements during visual search and memory search. Journal of Experimental Psychology, 1973, 98, 184-195.

Gould, J. D., \& Peeples, D. Eye movements during visual search and discrimination of meaningless, symbol, and object patterns. Journal of Experimental Psychology, 1970, 85, 51-55.

Graboi. D. Searching for targets: The effects of specific practice. Perception \& Psychophysics, 1971, 10, 300-304.

Juola, J. F., Fischler, I., Wood, C. T., \& Atkinson, R. C. Recognition time for information stored in long-term memory. Perception \& Psychophysics, 1971, 10, 8-14.

Metlay, W., Sokoloff, M., \& Kaplan, I. T. Visual search for multiple targets. Journal of Experimental Psychology, 1970, $85,148-150$.

Monty, R. A., Taub, H. A., \& Laughery, K. R. Keeping track of sequential events: Effects of rate, categories, and trial length. Journal of Experimental Psychology, 1965, 69, 224-229.

Neisser, U. Cognitive psychology. New York: Appleton-Century-Crofts, 1967.

Neisser, U. Decision-time without reaction time: Experiments in visual scanning. American Journal of Psychology, 1963. 76. 376-385.

Neisser, U., Novick, R.. \& Lazar, R. Searching for ten targets simultaneously. Perceptual \& Motor Skills, 1963, 17, 955-961.

Posner, M. L., \& Mitchell, R. F. Chronometric analysis of classification. Psychological Review, 1967, 74, 392-409.

Schoonard, J. W., \& Gould, J. D. Field of view and target uncertainty in visual search and inspection. Human Factors. 1973, 15, 33-42.

Segal. S. J., \& Fusella. V. Influence of imaged pictures and sounds on detection of visual and auditory signals. Journal of Experimental Psychology, 1970. 83. 458-464.

Shaffer, W. O., \& Shiffren. R. M. Rehearsal and storage of visual information. Journal of Experimental Psychology, 1972. 92. 292-296.

Smith. S. W.. Kincaid. W. M.. \& Semmelroth, C. Speed of visual target detection as a function of the density of confusion elements. University of Michigan Engineering Psycholog! Lah Report 2900-325-R. 1962. 
Sternberg, S. Two operations in character-recognition: Some evidence from reaction-time measurements. Perception \& Psychophysics, 1967, 2, 45-53.

Sternberg, $\mathrm{S}$. Decomposing mental processes with reaction-time data. Invited address, Midwestern Psychological Association meetings, 1971.

Sternberg, S., \& Scarbrough, D. L. Parallel testing of stimuli in visual search. Paper presented at International Symposium on Information Processing \& Control of Motor Activity, Bulgaria, 1969.

Wattenbarger, B. L. Speed and accuracy set in visual performance. Paper read at Midwestern Psychological Association meetings, Chicago, 1968.

Westcourt, K. T. \& Atkinson, R. C. Scanning for information in long- and short-term memory. Journal of Experimental Psychology, 1973, 98, 95-101.

Williams, L. G. The effects of target specification on objects fixated during visual search. Acta Psychologica, 1967, 27, 355-360.

Yntema, D. B. Keeping track of several things at once. Human Factors, 1963, 5, 7-17.

Yntema, D. B., \& Schulman, G. M. Response selection in keeping track of several things at once. Acta Psychologica, 1967, 27, 325-332.

Yonas, A., \& Pittenger, J. Learning to look for four things at once: $A$ test of simultaneous processing. Paper presented at Eastern Psychological Association meetings, Atlantic City, New Jersey, 1970.

\section{NOTES}

1. These reports have useful implications for the design of visual inspection systems. $\operatorname{Re}(a)$, in addition to positive and negative response buttons, an inspector should have an "undecided" button. Re (b), an inspection system should have a one-stimulus buffer which allows the item just inspected to be reclassified if the inspector desires.

2. An exception was the Trials by Background interaction, $F(6,12)=3.56, p<.05$, in which the first trial on a complex background was somewhat shorter than the other complex background trials.
3. Duncan range tests on the last 5 days of practice (Fig. 3a, FREQ = 1 curve) showed that search times were significantly slower at $\mathrm{N}=5$ than at $\mathrm{N}=10$ or $\mathrm{N}=1$, which did not differ significantly. However, I thank an anonymous referee for emphasizing the consistently faster search times at $N=1$ than at $N=10$ throughout practice. All Duncan range tests in this paper were done on the last 5 days of practice, Figs. 3 and 4 , and all were based upon the .05 significance level.

4. The reason $S$ probably identifies the target at $N=1$ and FREQ $>1$, even though logically he merely needs to count the number of occurrences of "a target" independent of its identification, is because nontarget targets also get displayed and these apparently are registered at some level as potential targets.

5. When FREQ $=1$ (Fig. $3 \mathrm{~b}$ ), search time per stimulus item was about $25 \mathrm{msec}$ more at $\mathrm{N}=10$ than at $\mathrm{N}=1$. When divided by target set size, this corresponds to a memory search rate of about $3 \mathrm{msec}$ per item, assuming serial processing of both stimulus items and target set items. Although these assumptions are probably not correct (cf. Sternberg \& Scarborough, 1969), the rate is close to the 5-6-msec search rate of long-term memory reported by Juola, Fischler, Wood, and Atkinson (1971).

6 . It is not necessary to assume parallel operation. In the serial version, the auditory comparison process is assumed to follow the visual comparison process if a visual match occurs. If no visual match occurs, the auditory comparison process is assumed to be skipped. Figure 5 can be simply modified to indicate this. A study just published by Westcourt and Atkinson (1973) concludes, however, that short-term memory (i.e., location of our rehearsal or "auditory" target subset) and long-term memory (i.e., location of our "visual" target sets), rather than being searched successively, are probably searched simultaneously.

7. This visual memory seems to be context specific; the same characters that popped out in the experiment did not pop out in other settings, e.g., books, magazines, signs, television.

8. Although the "pop-out" effect is phenomenally visual in this experiment, it is not limited to the visual modality. Familiar words, e.g., one's name, pop out from a conversational background.

(Received for publication October 27, 1972; revision accepted March 21, 1973.) 